\title{
Changes in precipitation and extreme precipitation in a warming environment in China
}

\author{
SUN JianQi ${ }^{1,2^{*}} \&$ AO Juan ${ }^{1,2,3}$ \\ ${ }^{1}$ Nansen-Zhu International Research Centre, Institute of Atmospheric Physics, Chinese Academy of Sciences, Beijing 100029, China; \\ ${ }^{2}$ Climate Change Research Center, Chinese Academy of Sciences, Beijing 100029, China; \\ ${ }^{3}$ Graduate University of Chinese Academy of Sciences, Beijing 100049, China
}

Received August 28, 2012; accepted October 9, 2012; published online November 27, 2012

\begin{abstract}
This study analyses the decadal changes in winter precipitation and extreme precipitation in a warming environment in China. The results show that, together with a trend of winter warming in China, winter precipitation and extreme precipitation in the region are also increasing. In addition, concurrent with the decadal warming shift that occurred in the mid-1980s, precipitation and extreme precipitation both increased significantly. Quantitative analysis shows that precipitation and extreme precipitation increased at rates of $9.7 \%$ and $22.6 \%$ per $1{ }^{\circ} \mathrm{C}$ of surface warming in China. This rate of precipitation increase is greater than the global mean, which indicates that precipitation in China is highly sensitive to climate warming and further highlights the importance of studying regional responses to climate warming. The fact that extreme precipitation is increasing at a higher rate than precipitation implies that winter precipitation in China will increasingly be of more extreme type in the context of global warming, which could partly explain why there have recently been a number of record-breaking extreme snowfall events in China.
\end{abstract}

winter precipitation, extreme precipitation, global warming, sensitivity, regional response, climate change

Citation: Sun J Q, Ao J. Changes in precipitation and extreme precipitation in a warming environment in China. Chin Sci Bull, 2013, 58: 1395-1401, doi: $10.1007 / \mathrm{s} 11434-012-5542-\mathrm{z}$

Air temperature and precipitation are the two primary meteorological elements. Their anomalous variability is always associated with frequent occurrences of extreme droughts/ floods and heat waves/cold surges, which have substantial and direct influences on society and the natural environment. Air temperature and precipitation have therefore been a point of focus for scientists and the general public alike. According to the Clausius-Clapeyron equation (CC), atmospheric water vapour and precipitation will increase by approximately $7 \%$ for each $1^{\circ} \mathrm{C}$ increase in temperature. Analysis of satellite observations and reanalysed data confirms the $\mathrm{CC}$ theoretical inference on the relationship between atmospheric water vapour and temperature $[1,2]$. However, the quantitative relationship between precipitation and temperature remains a matter of debate. Wentz et al. [2] reported that global mean precipitation increased at a rate of

*Corresponding author (email: sunjq@mail.iap.ac.cn) approximately 7.4 per $1^{\circ} \mathrm{C}$ between 1987 and 2006. The increasing rate of precipitation in this observation is much larger than what was found in model simulations, wherein precipitation increased only approximately $1 \%-3 \%$ per $1{ }^{\circ} \mathrm{C}$ [3]. Addressing the different responses of precipitation to temperature in the observations and simulations, Lambert et al. [4] raised questions regarding the method used by Wentz et al. [2] in calculating the sensitivity of precipitation to temperature. Using regression analysis, Lambert et al. [4] concluded that the rate of precipitation response to temperature calculated by Wentz et al. [2] is much higher. In addition, in the climate models, there are some uncertainties in simulating physical or chemical processes (e.g. variation of atmospheric aerosols and clouds and their effects on surface radiation, etc.). Such uncertainties introduce further uncertainty not only in temperature and precipitation changes but also in the rate at which precipitation changes with temperature [4]. If such uncertainties in the climate model are 
decreased, the response of precipitation to temperature in simulations can be understood as being comparable to the observed results [4]. Because only the period of 1987-2006 was used in the study by Wentz et al. [2], other researches have questioned whether such a short time period is sufficient to diagnose the response of precipitation to climate warming [5]. In theory, more credible results can be obtained from analyses of longer periods of time. However, if the period of analysis is extended to the past half-century (1951-2005), the results from different observation data are divergent and even reverse [6], which mainly results from the different quality of and spatial distribution in different observational data. It is, therefore, quite difficult to accurately diagnose the response of precipitation to temperature over a long time period on a global scale.

In contrast, in the past half-century, the data quality and spatial distribution in some regional precipitation observations is superior than that of global data. In addition, global warming does not mean that all regions of the Earth are warming, and the regional differences in climate are distinct [6]. It is, therefore, both more important and feasible to investigate the response of precipitation to temperature from a regional perspective. In the past half-century, China has been one of the regions with the greatest warming in the world. In this study, the relationship between precipitation and temperature in China will be emphasised.

In the past several decades, there have been a large number of studies on precipitation and extreme precipitation in China. Most of these valuable contributions to the literature were well reviewed in China's National Assessment Report on Climate Change, as well as in a number of other review papers [7-9]. However, there have only been a few works that have directly studied the sensitivity of precipitation to temperature. Qian et al. [10] suggested that the decrease in light rainfall is possibly related to the large-scale warming. Zhao et al. [11] compared the onset and end time of persistent rainfall in South and North China over different time periods (1980s-1990s and 1960s-1970s) and found that, compared to relatively cold periods (1960s-1970s), the persistent rainfall in South (North) China starts earlier (later) and terminates later (earlier) over relatively warmer time periods (1980s-1990s). All of these studies indicate that there could be a response in precipitation to climate warming. Because climate warming signals are strongest in winter, this study explores the qualitative and quantitative relationship of precipitation and extreme precipitation to winter temperatures in China.

\section{Data and methods}

Two observation datasets were used in this study. The observed daily temperature data are newly updated, homogenised temperatures gathered at China's 549 stations from the period of 1960-2008 that were developed by Li and Yan
[12]. The observed daily precipitation data from 756 stations in China were obtained from the National Meteorological Center of the China Meteorological Administration. The precipitation data are controlled for quality before they are released. Of these 756 stations, many have missing data points in the 1950s. Thus, this study focuses on the period from 1960 to 2008. The stations with missing data for more than $10 \%$ of days in a given year or $1 \%$ of days over the 48 -year period were not included. The missing daily records for the remainder of the stations have been filled in by their climatological values for the period of 1960-2008. Finally, temperature and precipitation data from a total of 535 stations were selected for analysis in this study.

The threshold for extreme precipitation is estimated based on percentiles. First, we calculate the 95th percentile of daily precipitation for all precipitation days of each winter from 1971 to 2000; the 30-year mean of the 95th percentile values is regarded as the extreme precipitation threshold. An extreme precipitation day is defined as a day in which precipitation is greater than the extreme precipitation threshold. Extreme precipitation for a winter is defined as the sum of precipitation on extreme precipitation days for a given winter, and total precipitation is defined as the sum of the precipitation on all precipitation days in a given winter.

\section{Results}

Before analysing the relationship of winter precipitation and extreme precipitation to temperature in China, it is important to first investigate the climatological features and trends in these three meteorological elements. As shown in Figure 1(a), winter temperature in China generally exhibits a meridional dipole pattern, namely temperatures to the north (south) of the line from the Shandong Peninsula southwestward to Southwest China are below (above) $0^{\circ} \mathrm{C}$. The temperature differences between the south and north flanks of China are larger than $40^{\circ} \mathrm{C}$, which indicates the multiplicity of climate types in China. In the past half-century, consistent with global warming, China has experienced a strong warming trend, with a larger amplitude over northern China and a smaller amplitude over southwest China.

Winter precipitation dominates southern China where the temperature is above $0^{\circ} \mathrm{C}$. This trend is mainly attributed to the warm-moist air that can easily reach southern China and create water vapour conditions for winter precipitation in the region. In contrast, northern China has significantly less winter precipitation. In particular, in the region extending from Inner Mongolia to southern Xinjiang, winter precipitation is less than $10 \mathrm{~mm}$. In wintertime, northern China experiences a strong winter monsoon, which brings cold-dry air from high latitudes and prevents the northward flow of warm-moist air from low latitudes. Consequently, there is less water vapour available to form precipitation over northern China, which is one of the main reasons for the lower 

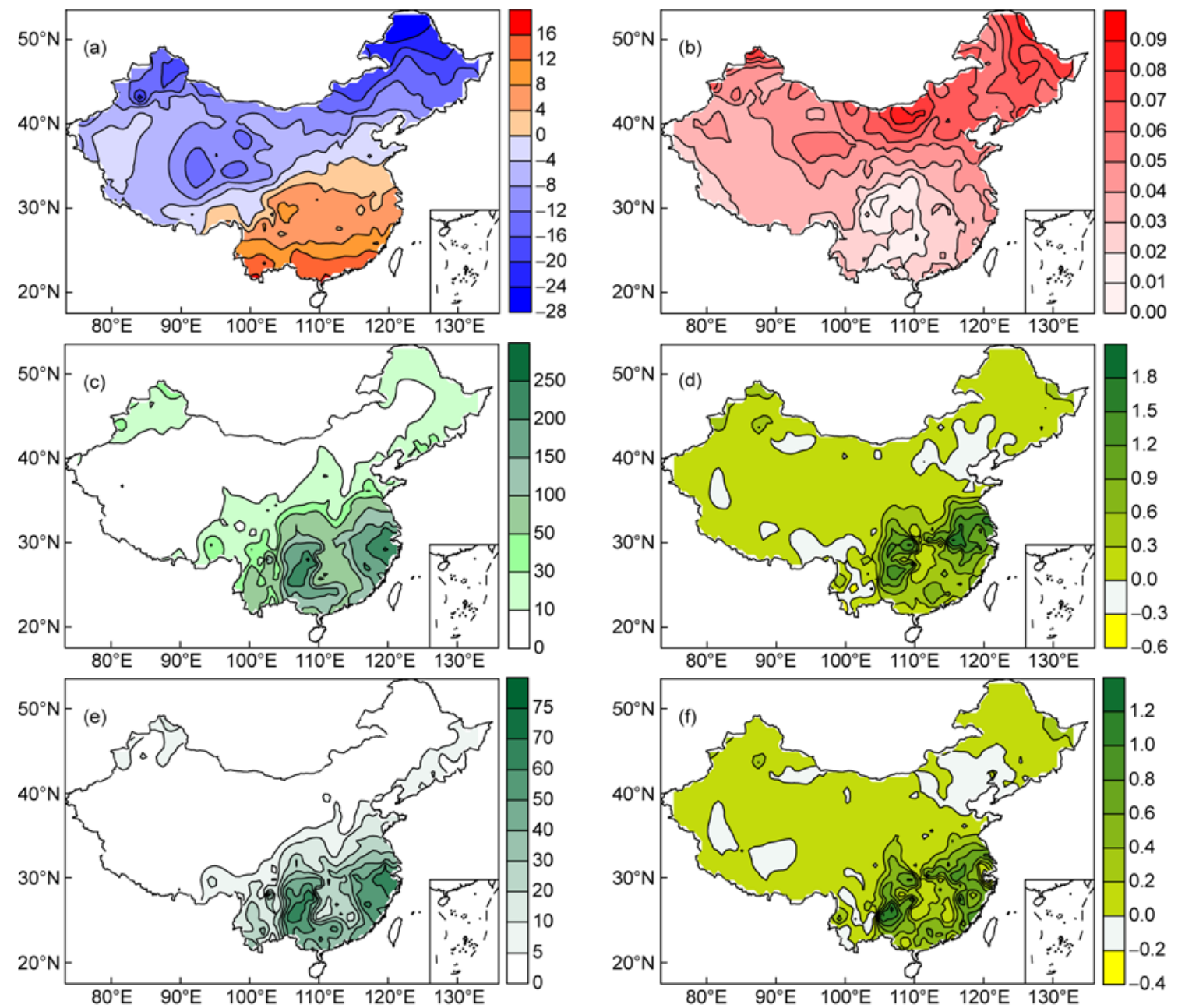

Figure 1 Winter climatology of temperature $\left({ }^{\circ} \mathrm{C}\right)(\mathrm{a})$, precipitation $(\mathrm{mm})(\mathrm{c})$, and extreme precipitation (mm) (e) over the period from $1960-2008$ and linear trends of these three variables ((b) temperature $\left({ }^{\circ} \mathrm{C} / \mathrm{a}\right),(\mathrm{d})$ precipitation $(\mathrm{mm} / \mathrm{a})$, and (f) extreme precipitation $\left.(\mathrm{mm} / \mathrm{a})\right)$ over the same period.

levels of winter precipitation in the region. The trend distribution shows that, with the exception of some small areas over North China and western China, winter precipitation over almost all of the country has increased, with large increases occurring over southern China. The distribution of winter extreme precipitation is very similar to that of precipitation. From a climatology perspective, extreme precipitation accounts for approximately one-third of the total precipitation. However, from the perspective of the trend, the value of extreme precipitation is much closer to that of total precipitation. Based on these results, we deduce that the increasing rate of extreme precipitation accounts for a large part of the total precipitation increase, which is further confirmed by the following quantitative analysis.

The pronounced climatology and trend analysis shows that, together with climate warming over the past half-century, winter precipitation and extreme precipitation have both increased, which implies that there could be a strong relationship between precipitation and temperature in China. The following analysis is performed based on this phenomenon. Considering that climate warming is phenomenon occurring over a long time scale, we first remove the interannual variability from all data via the nine-year moving mean method. This approach highlights the decadal features of precipitation and extreme precipitation, which are suitable for diagnosing their relationship with climate warming.

To investigate the relationship between precipitation and temperature, the singular value decomposition (SVD) method is used. This method can detect a coupled signal of two elements. The SVD results indicate that there is strong coupling between winter precipitation and temperature in China on the decadal time scale. The first mode accounts for $93.8 \%$ of the total square covariance. It is, therefore, reasonable to diagnose the relationship between precipitation and temperature by only analysing the first mode situation. Figure 2 shows the first paired modes of winter precipitation and temperature, as well as their corresponding expansion time series. The temperature mode exhibits a consistent warming pattern over the country, with larger (smaller) values over northern (southern) China. This temperature distribution is quite similar to the warming trend in China over the past half-century, as shown in Figure 1(b). The 

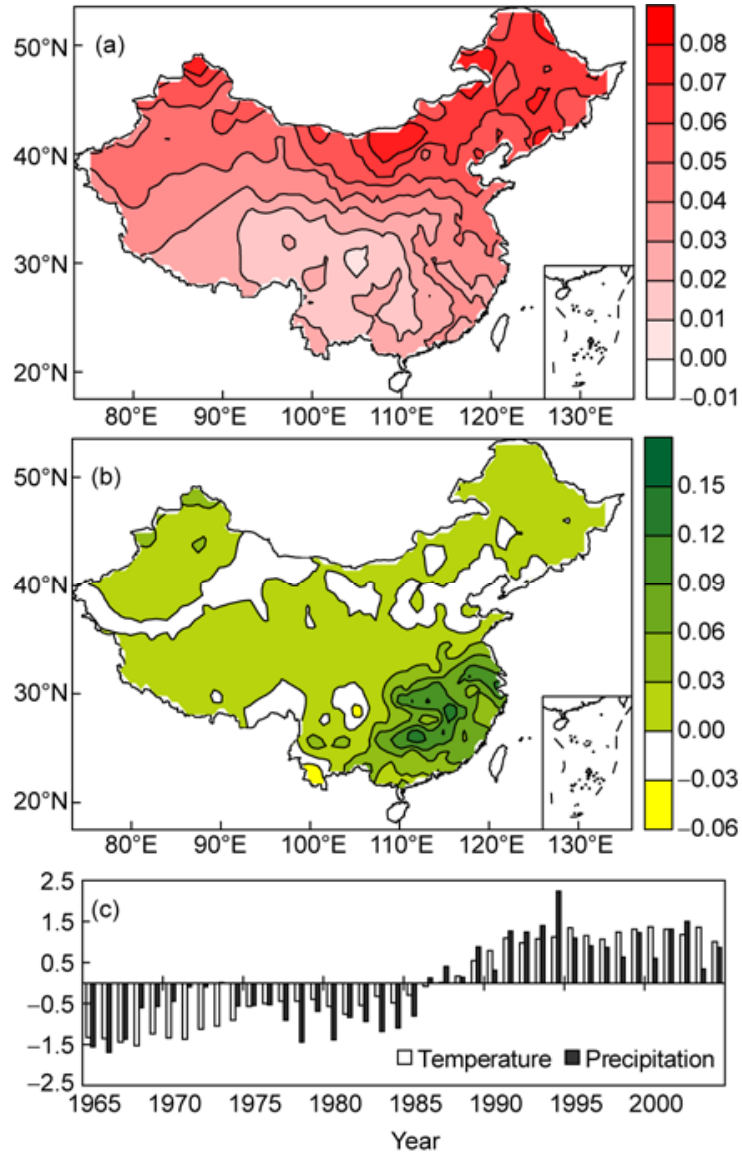

Figure 2 First paired mode of temperature (a) and precipitation (b) and their corresponding normalised time series (c).

corresponding temperature time series shows an increasing trend and exhibits an abrupt decadal change around the mid-1980s, which is consistent with the warming trend in China during the past half-century [13]. Therefore, the temperature mode of the SVD and its related expansion time series reflect the winter warming features of China, which provides a solid basis for exploring the response of precipitation to climate warming in the country.

Figure 2(b) shows the SVD precipitation mode, which is related to climate warming in China. As compared to the temperature mode, the precipitation mode shows a relative weaker spatial consistency. There are some small negative value regions dispersed over southern Northeast China, northern North China, Northwest China, the southern region of the Tibetan Plateau, and Southwest China. However, these negative values are small, and most parts of China show consistent, large-scale positive values. Considering that climate warming is a large-scale phenomenon, in this study we will only focus on the consistent, large-scale changes in precipitation and ignore the pronounced small, localised negative signals of precipitation. Accordingly, it can be concluded that increases in winter precipitation in China are associated with a warming environment, and the region with the greatest increase is southern China. The two corresponding expansion time series of the first paired modes co-vary very well. Their correlation coefficient is 0.83 , and they both show an abrupt decadal change around the mid-1980s. These results further confirm that there is strong coupling between winter precipitation and temperature in China: as climate warming increases, so does the rate of winter precipitation.

The above SVD analysis describes the seasonal mean precipitation. Now, SVD analysis is employed to further consider the coupling relationship between winter extreme precipitation and temperature. Figure 3(a) shows that the temperature mode of SVD has a similar distribution with that of the climate warming trend in China: all of the country is warming, with larger (less) value regions in northern (southern) China, which indicates that the temperature mode of SVD also reflects the warming features of China over the past half-century. Figure 3(b) depicts the extreme precipitation mode of SVD. The extreme precipitation mode is similar to that of precipitation, presented in Figure 2(b). Except for some small negative centres over southern Northeast China, northern North China, Northwest China, the southern region of the Tibetan Plateau, and Southwest China, the
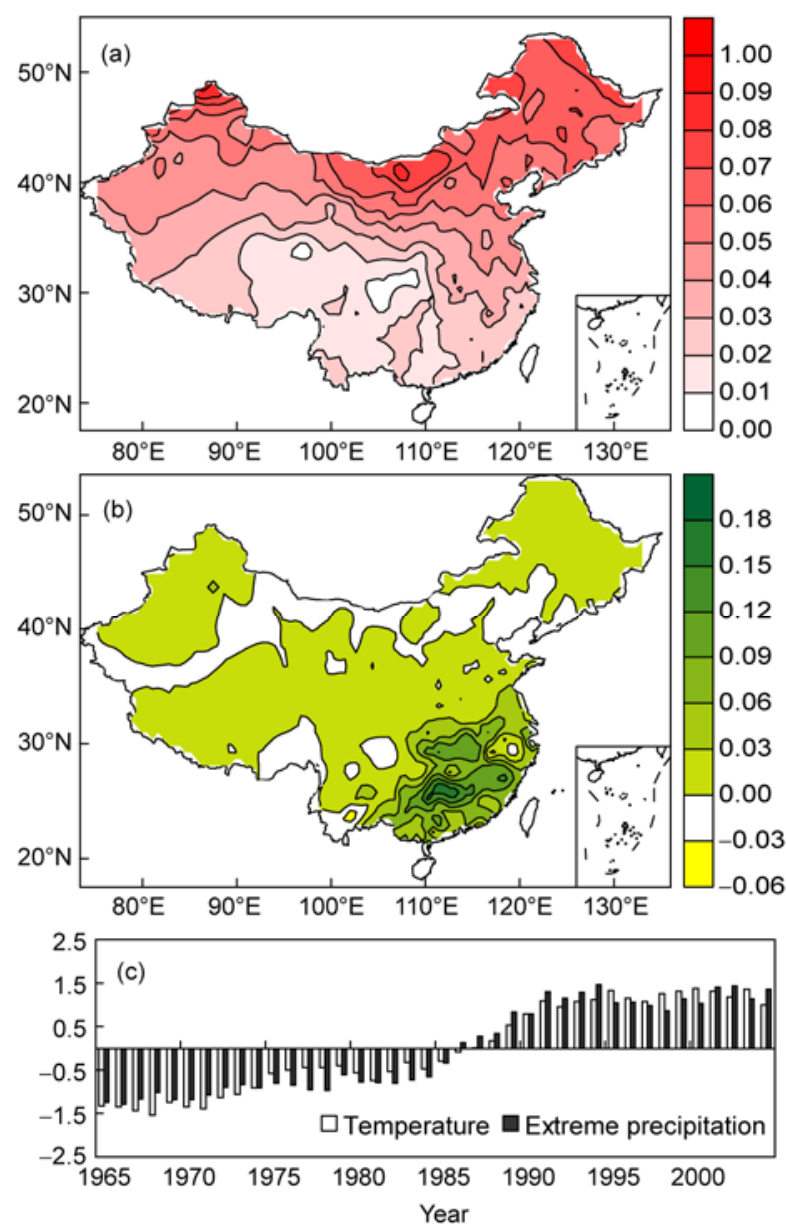

Figure 3 First paired mode of temperature (a) and extreme precipitation (b) and their corresponding normalised time series (c). 
extreme precipitation over most parts of China is increasing together with climate warming. The correlation coefficient between the two corresponding time series of extreme precipitation and temperature is 0.92 , which is higher than that between precipitation and temperature. In addition, the first mode of extreme precipitation and temperature accounts for $95.4 \%$ of the total square covariance, which is also higher than that of precipitation and temperature. All of these results indicate that there is a stronger coupling relationship between extreme precipitation and temperature, relative to that of precipitation and temperature.

The pronounced SVD analysis suggests that there is a close relationship between winter precipitation and extreme precipitation to temperature in China. How strong is the response of winter precipitation and extreme precipitation to warming in China? To answer this question, the quantitative relationship of winter precipitation and extreme precipitation with temperature is studied from the country mean perspective. To calculate the country mean time series, the station data are first interpolated to a $2^{\circ} \times 2^{\circ}$ grid using the Cressman interpolation method. The China mean time series for temperature, extreme precipitation, and temperature are computed by area-weighting the average of these three meteorological variables over grids for the whole country. Table 1 shows the correlation coefficients between the SVD expansion time series and the China mean time series for precipitation, extreme precipitation, and temperature. The table suggests that all of the correlation coefficients are greater than 0.93, which implies that the China mean time series reflect the decadal variability features of China's winter precipitation, extreme precipitation, and temperature and their coupling relationship, as revealed in SVD analysis. It is therefore reasonable to determine the quantitative coupling relationship of precipitation and extreme precipitation with temperature using the China mean time series to substitute the SVD time series. Figure 4(a) and (b) presents the scatter plots of precipitation and temperature (extreme precipitation and temperature) anomalies (relative to the climatology of 1965-2004). These two figures suggest that there is a strong linear relationship between precipitation and extreme precipitation and temperature. In addition to

Table 1 Correlation coefficient between the China mean time series of temperature, precipitation, and extreme precipitation and the corresponding time series of the SVD first mode over the period of 1965-2004 ${ }^{\text {a) }}$

\begin{tabular}{lc}
\hline & Correlation coefficients \\
\hline SVD-T $T_{\text {EP Vs. T }}$ & 1.00 \\
SVD-TP Vs. T & 1.00 \\
SVD-EP vs. EP & 0.95 \\
SVD-P vs. P & 0.93 \\
\hline
\end{tabular}

a) T/P/EP indicates the China mean time series of temperature/precipitation/extreme precipitation. SVD- $\mathrm{T}_{\mathrm{P}} / \mathrm{SVD}-\mathrm{P}\left(\mathrm{SVD}-\mathrm{T}_{\mathrm{EP}} / \mathrm{SVD}-\mathrm{EP}\right)$ indicates the time series of SVD analysis of precipitation and temperature (extreme precipitation and temperature).
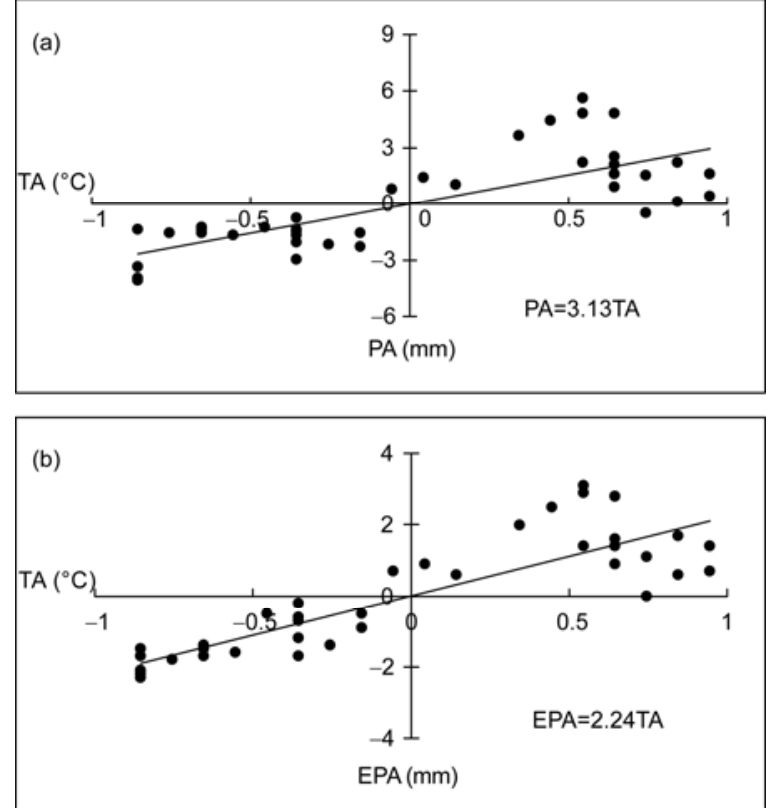

Figure 4 Scatter plots for winter temperature anomalies (relative to 19652004) and precipitation anomalies (a) and for winter temperature anomalies (b) and extreme precipitation anomalies. The linear regression formulas are presented in the lower right corners of the figures.

increasing winter temperatures in China, winter precipitation and extreme precipitation have both increased in the region, which is consistent with the pronounced SVD result.

The quantitative coupling relationship of precipitation and extreme precipitation to temperature is assessed using the linear regression method. Lambert et al. [4] suggest that diagnosing the response of precipitation to climate warming using the linear regression method is more reasonable. The linear regression formulas for precipitation and extreme precipitation with temperature are presented in the lower right corner of Figure 4 . The formulas show that precipitation and extreme precipitation increased by 3.1 and $2.2 \mathrm{~mm}$, respectively, corresponding to a $1{ }^{\circ} \mathrm{C}$ increase in temperature. If these increased precipitation and extreme precipitation values are divided by their climatology (averaged over the period of 1965-2004), winter precipitation and extreme precipitation increase at rates of $9.7 \%$ per $1{ }^{\circ} \mathrm{C}$ and $22.6 \%$ per $1^{\circ} \mathrm{C}$, respectively. The increasing amount of extreme precipitation accounts for $71.6 \%$ of the total precipitation increase, implying that the increase of winter extreme precipitation is much larger than that of precipitation in a warming environment in China. This phenomenon coincides with the recent occurrence of many record-breaking snowfall events in China [14-16] and with projections of increased winter precipitation and extreme weather events in China in the context of climate warming $[17,18]$.

\section{Summary and discussion}

This study analyses the coupling relationships between winter 
temperature and precipitation as well as extreme precipitation in China. The results indicate that over the past half-century, winter precipitation and extreme precipitation show consistent variability with the temperature on a decadal time scale. In addition to increasing temperature, precipitation and extreme precipitation have also increased, and these three variables consistently demonstrate an abrupt decadal change around the mid-1980s. Previous studies have shown that the East Asian winter monsoon (EAWM) experienced an abrupt decadal change around the mid1980s [19,20], after which it became weaker, The weakening of the EAWM during the past several decades could be related to climate warming, because simulations of coupled climate models show that the EASM will decrease under the warming background [21]. The weakened EAWM further weakens the control of its related cold-dry air over East Asia, favouring the northward flow of warm-moist air from low latitudes and the ocean. Consequently, in a weaker EAWM year, there is more winter precipitation over China, in particular over southern China [22,23]. These results are consistent with the distribution of winter precipitation and extreme precipitation associated with climate warming in China. Therefore, the coupling relationship of winter precipitation and extreme precipitation with climate warming over China can be physically explained via the EAWM variability. The quantitative analysis shows that winter precipitation and extreme precipitation are increasing at rates of $9.7 \%$ per $1^{\circ} \mathrm{C}$ and $22.6 \%$ per $1^{\circ} \mathrm{C}$, respectively. The increasing amount of extreme precipitation accounts for $71.6 \%$ of the total precipitation increase, implying that winter precipitation will increasingly be of more extreme type as global warming increases.

To compare the sensitivity of precipitation and extreme precipitation to climate warming in winter, we also briefly investigate the relationship of precipitation and extreme precipitation with temperature in summer. The results suggests that in summer, precipitation and extreme precipitation also increased together with increasing temperature at rates of $6.7 \%$ per $1{ }^{\circ} \mathrm{C}$ and $15.4 \%$ per $1{ }^{\circ} \mathrm{C}$; the rate of increase in summer is less than that in winter. These results indicate that the response of precipitation and extreme precipitation is stronger in winter, the season with greater warming, which further suggests that investigating the seasonal impact of warming offers more comprehensive data.

The rates of increased winter precipitation and extreme precipitation are $9.7 \%$ per $1{ }^{\circ} \mathrm{C}$ and $22.6 \%$ per $1{ }^{\circ} \mathrm{C}$, which is greater than that of the global mean [2-4]. One of the possible reasons for the differences in rate between China's mean and the global mean is that the global mean result is calculated from the annual mean, while in this study the China mean result focuses on winter. It is well known that winter is the season with the greatest warming. If precipitation responds to global warming, the response may be strongest in winter. Therefore, it is reasonable that the increasing rate of winter precipitation evidenced in the China mean is greater than that of annual rate of precipitation for the global mean. In addition, global warming is not spatially consistent worldwide, and precipitation has strong regional features. It is also reasonable that the response of precipitation is stronger in certain regions and is weaker in others. The results of this study indicate that the response of winter precipitation to temperature in China is stronger than the global mean. This difference underscores the importance of examining the impact of climate warming on a regional scale. We should examine the impact of climate warming from a regional as well as global perspective, which will enable a more comprehensive picture of the impact of climate warming and provide information for developing adaptation strategies.

This work was supported by the Strategic Priority Research ProgramClimate Change: Carbon Budget and Relevant Issues of the Chinese Academy of Sciences (XDA05090306) and the National Basic Research Program of China (2012CB955401).

1 Trenberth K E, Fasullo J, Smith L. Trends and variability in columnintegrated atmospheric water vapor. Clim Dyn, 2005, 24: 741-758

2 Wentz F J, Ricciardulli L, Hilburn K, et al. How much more rain will global warming bring? Science, 2007, 317: 233-235

3 Held I M, Soden B J. Robust responses of the hydrological cycle to global warming. J Clim, 2006, 19: 5686-5699

4 Lambert F H, Stine A R, Krakauer N Y. How much will precipitation increase with global warming? EOS, 2008, 89: 193-200

5 Previdi M, Liepert B G. Interdecadal variability of rainfall on a warming planet. EOS, 2008, 89: 193-195

6 Trenberth K E, Jones P D, Ambenje P, et al. Observations: Surface and atmospheric climate change. In: Solomon S, Qin D, Manning M, et al., eds. Climate Change 2007: The Physical Science Basis. Contribution of Working Group I to the Fourth Assessment Report of the Intergovernmental Panel on Climate Change. Cambridge and New York: Cambridge University Press, 2007. 254-265

7 Committee of China's National Assessment Report on Climate Change. China's National Assessment Report on Climate Change (in Chinese). Beijing: Science Press, 2007. 18-42

8 Zhai P M, Pan X H. Trends in temperature extremes during 19511999 in China. Geophys Res Lett, 2003, 30: 1913-1916

9 Wang H J, Sun J Q, Chen H P, et al. Extreme climate in China: Factors, simulation and projection. Meteorol Z, 2012, doi: 10.1127/09412948/2012/0330

10 Qian W H, Fu J L, Yan Z W. Decrease of light rain events in summer associated with a warming environment in China during 1961-2005. Geophys Res Lett, 2007, 34: L11705

11 Zhao P, Yang S, Yu R C. Long-term changes in rainfall over eastern China and large-scale atmospheric circulation associated with recent global warming. J Clim, 2009, 23: 1544-1562

$12 \mathrm{Li} Z$, Yan Z W. Homogenized daily mean/maximum/minimum temperature series for China from 1960-2008. Atmos Oceanic Sci Lett, 2009, 2: 237-243

13 Ren G Y, Guo J, Xu M Z, et al. Climate changes of China's mainland over the past half century (in Chinese). Acta Meteorol Sin, 2005, 63: 942-956

14 Ding Y H, Wang Z Y, Song Y F, et al. Causes of the unprecedented freezing disaster in January 2008 and its possible association with the global warming (in Chinese). Acta Meteorol Sin, 2008, 66: 808-825

15 Sun J Q, Wang H J, Yuan W. A preliminary investigation on causes of the catastrophic snowstorm in March, 2007 in the northeastern parts of China (in Chinese). Acta Meteorol Sin, 2009, 67: 469-477

16 Wang H J, Yu E T, Yang S. An exceptionally heavy snowfall in 
Northeast China: Large-scale circulation anomalies and hindcast of the NCAR WRF model. Meteorol Atmos Phys, 2011, 113: 11-25

17 Sun J Q, Wang H J, Yuan W. Spatial-temporal features of intense snowfall events in China and their possible change. J Geophys Res, 2010, 115: D16110

18 Gao X J, Shi Y, Zhang D F, et al. Climate change in China in the 21st century as simulated by a high resolution regional climate model. Chin Sci Bull, 2012, 57: 1188-1195

19 Wang H J, He S P. Weakening relationship between East Asian winter monsoon and ENSO after mid-1970s. Chin Sci Bull, 2012, 57: $3535-3540$
20 He S P, Wang H J. An integrated East Asian winter monsoon index and its interannual variability (in Chinese). Chin J Atmos Sci, 2012, 36: $523-538$

21 Hori M E, Ueda H. Impact of global warming on the East Asian winter monsoon as revealed by nine coupled atmosphere-ocean GCMs. Geophys Res Lett, 2006, 33: L03713

22 Zhou L T. Impact of East Asian winter monsoon on rainfall over southeastern China and its dynamical process. Int J Climatol, 2011, 31: 677-686

23 Wang L, Feng J. Two major modes of the wintertime precipitation over China (in Chinese). Chin J Atmos Sci, 2011, 35: 1105-1116

Open Access This article is distributed under the terms of the Creative Commons Attribution License which permits any use, distribution, and reproduction in any medium, provided the original author(s) and source are credited. 